\title{
CD133 correlation with chemoradiotherapy resistance in rectal cancer.
}

\author{
Jinghua Huang*, Yongan Fu, Zongda Cai \\ Department of General Surgery, Affiliated Quanzhou First Hospital, Fujian Medical University, Quanzhou, Fujian, \\ PR China
}

\begin{abstract}
CD133 is a type of a biomarker of rectal cancer stem cells. Recent research suggested that colorectal cancer stem cells have the radiotherapy and chemotherapy resistance. This study intends to explore CD133 expression in rectal cancer and its correlation with Chemoradiotherapy (CRT) resistance. Cancer tissues were collected from 56 rectal cancer patients receiving surgical treatment and CRT. CD133 positive expression rate in cancer tissue was detected by immunohistochemistry. Colorectal cancer cell line HT-29 was transfected with CD133 plasmid. CD133 protein level was determined by Western blot. Cell survival rate was tested by colony formation assay. Immunohistochemistry results showed that $\mathrm{CD133}$ positive rate in rectal cancer patients received CRT achieved $71.4 \%$. Its positive rate reached $89.2 \%$ in patients with ineffective CRT treatment, which was obviously higher than that in effective treatment group as $36.8 \%(P<\mathbf{0 . 0 5})$. CD133 was successfully transfected to HT-29 cells, resulting in $\mathrm{CD133}$ overexpression compared with control $(\mathbf{P}<\mathbf{0 . 0 5})$. Cell survival detection demonstrated that it was markedly higher in CD133 overexpressed HT-29 cells receiving radiotherapy $(\mathbf{P}<\mathbf{0 . 0 5})$. CD133 positive expression rate elevated in rectal cancer patients after CRT treatment. CD133 expression may be related to cancer cell CRT resistance.
\end{abstract}

Keywords: Rectal cancer, CD133, Chemoradiotherapy, Resistance.

Accepted on October 27, 2017

\section{Introduction}

Colorectal cancer is one of the most common malignant tumors in digestive tract, of which about $25 \%$ were rectal cancer patients [1]. At present, total mesorectal excision combined preoperative Chemoradiotherapy (CRT) is the main treatment method for rectal cancer. However, postoperative recurrence and CRT resistance continuously plagued medical staff [2]. Clarifying the molecular mechanism of CRT resistance in rectal cancer is of great significance for improving the prognosis and treatment efficacy for rectal cancer patient.

Cancer Stem Cells (CSCs) are a special kind of cancer cells that have the ability of self-renewal and differentiating to other cells [3]. CSCs have been found in many human malignant tumors including rectal cancer [4-6]. Recent studies reported that CSCs has strong resistance to CRT, and some researchers believed that the CRT resistance of CSCs is caused by abnormal CD133 expression level [7,8]. CD133 is a kind of transmembrane glycoprotein. It was found that CD133 is the positive biomarker of CSCs. CD133 positive colorectal cancer cells may form tumor again after surgery and CRT $[9,10]$. This study intends to explore CD133 expression in rectal cancer and its correlation with CRT resistance.

\section{Materials and Methods}

\section{Object selection}

A total of 56 cases of rectal cancer patients in the Affiliated Quanzhou First Hospital, Fujian Medical University between January 2009 and March 2016 were enrolled with the mean age at $63.6 \pm 9.5 \mathrm{y}$ old. All the patients were graded according to the TNM staging. There were 19 cases in stage II and 37 cases in stage III. All the rectal patients received total mesorectal excision combined CRT. Another 40 cases of rectal cancer patients that did not receive CRT were selected as control.

The study protocol was approved by the Affiliated Quanzhou First Hospital, Fujian Medical University, and all patients gave their informed consent before study commencement.

\section{Reagents and instruments}

Cell and tissue RNA extraction kit was from QIAGEN. RTPCR kit was from TIANGEN. Gel imaging system was provided by Shanghai Peiqing technology co., LTD. Antibodies were from Proteintech. DAB color-substrate solution was from Boster. 


\section{CRT treatment}

All the patients in experimental group received CRT. Specially, all patients received four courses of chemotherapy with 5fluorouracil. 5-fluorouracil was continuous dripped at 600 $\mathrm{mg} / \mathrm{m}^{2}$ for $24 \mathrm{~h}$. Meanwhile, 5-fluorouracil was also orally taken at $400 \mathrm{mg} / \mathrm{m}^{2}$ for five consecutive days. Radiotherapy was performed simultaneously with chemotherapy at 20-45 Gy. Mandard Tumor Regression (TRG) score was applied to evaluate the pathological reaction after CRT treatment, including TRG1, complete response; TRG2, partly response or residual tiny tumor cells; TRG3, moderate response or residual tumor cells or cell group; TRG4, obvious tumor cell group in the lesions with less than $25 \%$ fibrosis; TRG5, no response. TRG1-3 demonstrated good CRT response, while TRG4-5 showed poor CRT response [11].

The patients received total mesorectal excision at $6 \sim 8 \mathrm{~W}$ after CRT. The samples were collected in the surgery and stored in liquid nitrogen or fixed. The samples were sliced for histological grading and immunohistochemistry.

\section{Immunohistochemistry}

CD133 expression in rectal cancer tissue was detected by immunohistochemistry. The section was blocked by 5\% BSA after dewaxing and hydration. Next, the section was incubated in CD133 primary antibody and secondary antibody. After added with HRP coupled streptavidin and washed, the section was developed by DAB. Then the section was redyed by hematoxylin. After dehydration, hyalinization, and sealing, the section was examined under microscope. The results were evaluated by semi-quantitative method. Tan granule appeared in the cell was considered as positive. CD133 positive sample was considered as positive cell number $>40 \%$ of total cell number.

\section{Cell culture and transfection}

Human rectal cancer cell line HT-29 was bought from Chinese academy of sciences, Shanghai institutes for cell resource center. The cells were cultured in RPMI 1640 containing $10 \%$ fetal calf serum, $2 \mathrm{mM}$ glutamine, $50 \mathrm{U} / \mathrm{ml}$ penicillin, $50 \mathrm{U} / \mathrm{ml}$ streptomycin, and $20 \mathrm{U} / \mathrm{ml}$ gentamicin. The cells were maintained in $37^{\circ} \mathrm{C}$ and $5 \% \mathrm{CO}_{2}$ [12].

CD133 overexpression vector pcDNA3.1-CD133 was constructed based on pcDNA3.1 according to human CD133 cDNA sequence. The vector was transfected to HT-29 cells using lipofectamine INTERFERinTM transfection reagent kit (Polyplus transfection) according to the manual.

\section{Western blot}

HT-29 cells in logarithmic phase were digested by enzyme and seeded in 24-well plate. After treated by BRP for $24 \mathrm{~h}$, the cells were collected to extract total protein. The protein was separated by SDS-PAGE and transfected to membrane. After blocked by $5 \%$ skim milk, the membrane was incubated in primary antibodies (CD133 and $\beta$-actin) and HRP-tagged secondary antibody $(1: 1000)$. After developed by DAB, the band was analysed by gel imaging system to calculate the relative expression level [13].

\section{Radiotherapy}

After transfection, HT-29 cells in logarithmic phase were seeded in $100 \mathrm{~mm}$ dish at 104 cells. The cells received different doses of radiation at 0,1 , and $2.5 \mathrm{~Gy}$. Then the cells were further cultured in incubator.

\section{Colony formation assay}

HT-29 cells receiving different radiotherapy were digested and seeded in dish with $10 \mathrm{ml}$ medium at 100 cells with three replicates. Then the cells were cultured in incubator 10 days and washed by PBS. Next, the cells were fixed by $2 \%$ paraformaldehyde for $15 \mathrm{~min}$ and stained by $5 \%$ crystal violet for $15 \mathrm{~min}$. Colony number was counted to calculate colony formation rate. Colony formation rate $=($ clone number $/ 100) \times$ $100 \%[14]$.

\section{Statistical analysis}

All the data was presented as mean \pm standard deviation. The statistical analysis was performed on Stat View 5.0 software. ANOVA was applied for difference comparison. $\mathrm{P}<0.05$ was considered as statistical significance.

\section{Results}

\section{CD133 expression in rectal cancer}

All the rectal patients received immunohistochemical detection to analyse CD133 expression in rectal cancer cells. As shown in Figure 1, there were three types of immunohistochemistry results. Firstly, CD133 negative. Secondly, brown particles appeared on the surface of cavity. Thirdly, brown particles appeared in the cytoplasm. Only the patients with the third result were defined as CD133 positive.

\section{CD133 expression changes after CRT treatment}

Rectal cancer tissues in experimental group and control were stained for immunohistochemistry to analyse CD133 positive rate after different treatment strategies. As shown in Table 1, CD133 expressed both in patients received CRT treatment or no CRT treatment. CD133 positive rate was only $20 \%$ in patients did not receive CRT treatment, while it was $71.4 \%$ in patients received CRT treatment. Its positive rate was $36.8 \%$ (7/19) in patients with effective CRT treatment, which was obviously lower than that in ineffective treatment group as $89.2 \%(33 / 37)$.

\section{CD133 overexpression in rectal cancer cell line}

CD133 plasmid was transfected to rectal cancer cell line HT-29. Western blot was adopted to test CD133 expression level (Figure 2). The results showed that CD133 level was 
significantly higher after transfection, suggesting that CD133 was successfully overexpressed in HT-29 cells.

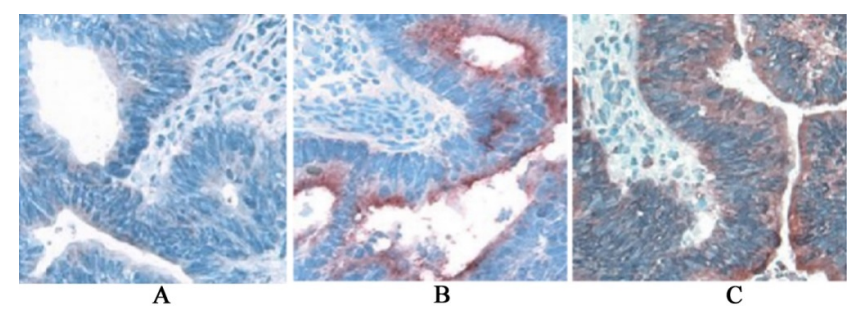

Figure 1. CD133 immunohistochemistry in rectal cancer tissue. A, CD133 negative. $B$, brown particles appeared on the surface of cavity. C, brown particles appeared in the cytoplasm, CD133 positive.
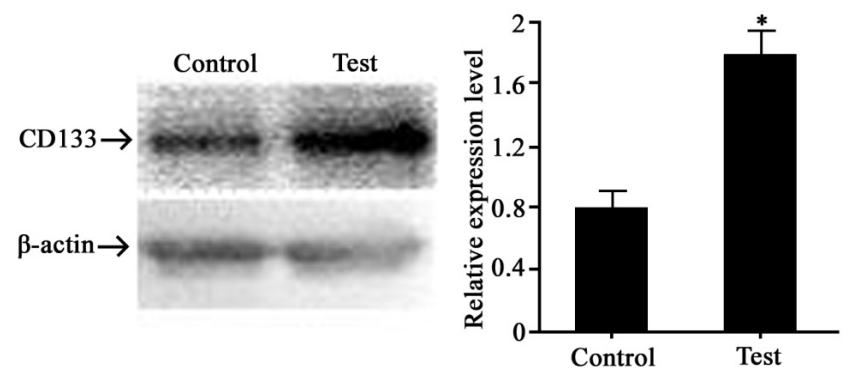

Figure 2. CD133 expression after transfection. ${ }^{*} P<0.05$, compared with control.

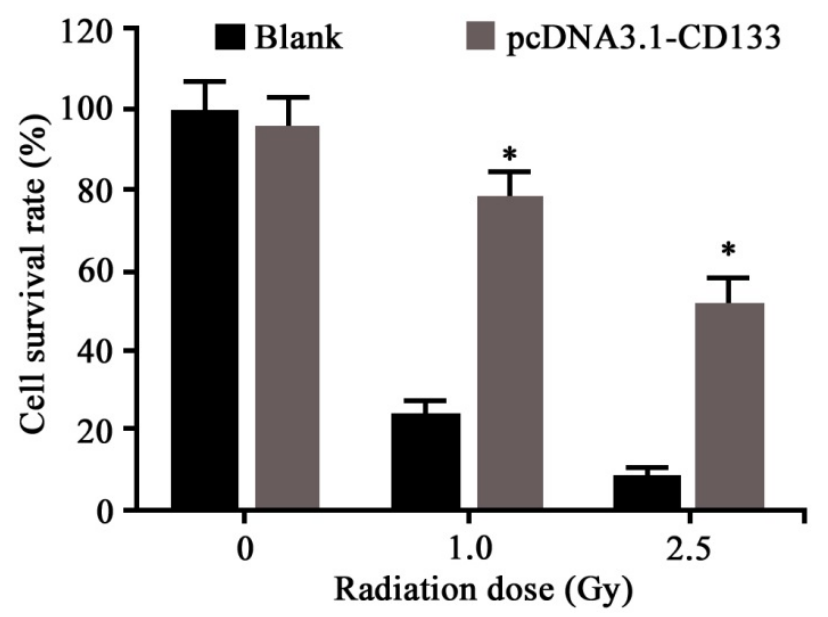

Figure 3. Different radiation doses impact on cell survival. ${ }^{*} P<0.05$, compared with control.

\section{The impact of CD133 expression on cell survival}

Different doses of radiation was applied on CD133 overexpressed HT-29 cells. Colony formation assay was used to test cell survival (Figure 3). No statistical difference was observed between CD133 overexpressed HT-29 cells and control when the radiation dose was 0 . However, the survival rate of HT-29 transfected with CD133 was obviously higher than the control when the radiation dose larger than 1 Gy $(\mathrm{P}<0.05)$.

\section{Discussion}

It is generally believed that CSCs cells play an important role in the process of malignant tumor resistance and postoperative recurrence [7]. Many studies confirmed that CD133 positive expression was an important index to distinguish CSCs in malignant tumor cells, including colorectal cancer $[10,13,14]$. Thus, it was speculated that CD133 positive expression may be correlated to rectal cancer CRT resistance.

This study compared CD133 expression in rectal cancer tissues between patients received CRT or no CRT. The results showed that $\mathrm{CD} 133$ positive rate in rectal cancer patients received CRT were obviously higher than those received no CRT. Moreover, it was also demonstrated that CD133 positive rate in patients with ineffective CRT was significantly higher than those with effective CRT. KAWAMOTO found that radiotherapy markedly elevated CD133 mRNA level in rectal cancer cell line [15], which was consistent with our results. It also indicated that radiotherapy can induce CD133 enhancement in rectal cancer cells. Meanwhile, radiotherapy causes CSCs enrichment, leading to higher CD133 positive rate [16].

To explore the relationship between CD133 expression and rectal cancer cells CRT resistance, we overexpressed CD133 in HT-29 cells and detected cell survival under different radiotherapy doses. The results demonstrated that CD133 overexpression may enhance HT-29 cell survival under radiation. Hongo and Kure also got similar results. Based on the abovementioned research, we speculate that CD133 positive expression may be related to the rectal cancer patients CRT resistance $[17,18]$.

At present, the specific effects of CD133 are still unclear. Researchers have not found the ligand of CD133, and also fail to find the interaction between CD133 molecular and signaling pathways. However, CD133 abnormal expression is associated with autosomal recessive inheritance and retinal degeneration. James pointed out that it could be due to CD133 overexpression can promote BAX expression, thereby reducing cells apoptosis [19]. It was also found that P53 protein level significantly elevated in $\mathrm{CD}_{133^{+}}$cancer cells after radiotherapy, which can enhance cell DNA damage repair ability and improve resistance to CRT [20,21].

Rectal cancer is a type of digestive tract malignant tumor that seriously harms to patient's health. Postoperative recurrence and CRT resistance keep in trouble medical personnel in rectal cancer treatment process. Our results found there was an association between CD133 expression in cancer tissue and CRT effect. CD133 positive rate was lower in CRT effective patients, which could be used to predict the curative effect, so as to reduce patient's burden. At the same time, the relationship between CD133 expression and CRT resistance also implies that we should take CD133 as treatment target for rectal cancer in the future. Some researchers are trying to develop a CD133 monoclonal antibody drug, and couple drug molecule to chemotherapy drugs, in hope to kill the CSCs in malignant tumor cells. It may decline postoperative recurrence and CRT 
resistance, reduce patient's pressure, and improve the treatment efficiency.

Table 1. CD133 expression in rectal cancer patients receiving different treatment strategies.

\begin{tabular}{|c|c|c|c|c|c|c|}
\hline & \multicolumn{3}{|c|}{ CRT group $(n=56)$} & \multicolumn{3}{|c|}{ No CRT group $(n=40)$} \\
\hline & Total number & CD133 positive number & Positive rate & Total number & CD133 positive number & Positive rate \\
\hline \multicolumn{7}{|l|}{ Age $(y)$} \\
\hline$\geq 65$ & 30 & 24 & $80 \%$ & 24 & 5 & $20.80 \%$ \\
\hline$<65$ & 26 & 16 & $61.50 \%$ & 16 & 3 & $18.80 \%$ \\
\hline \multicolumn{7}{|l|}{ Gender } \\
\hline Male & 38 & 27 & $71.10 \%$ & 26 & 5 & $19.20 \%$ \\
\hline Female & 18 & 13 & $72.20 \%$ & 14 & 3 & $21.40 \%$ \\
\hline \multicolumn{7}{|c|}{ TNM stage } \\
\hline $\mathrm{T} \mathrm{l} / \mathrm{II}$ & 20 & 11 & $55 \%$ & 15 & 1 & $6.70 \%$ \\
\hline T III/IV & 36 & 29 & $80.60 \%$ & 25 & 7 & $28 \%$ \\
\hline \multicolumn{7}{|c|}{ TRG grade } \\
\hline Level 1-3 & 19 & 7 & $36.80 \%$ & - & - & - \\
\hline Level 4-5 & 37 & 33 & $89.20 \%$ & - & - & - \\
\hline \multicolumn{7}{|c|}{ Recurrence } \\
\hline Yes & 18 & 17 & $94.40 \%$ & 17 & 6 & $35.30 \%$ \\
\hline No & 38 & 23 & $60.50 \%$ & 23 & 2 & $8.70 \%$ \\
\hline
\end{tabular}

\section{Acknowledgments}

This work was supported by Guangdong science and technology project (2017A020215036).

\section{References}

1. Siegel R, Desantis C, Jemal A. Colorectal cancer statistics, 2014. CA Cancer J Clin 2014; 64: 104-117.

2. Kudjawu YC, Eilstein D, Decool E, De Maria F, Beltzer N, Chatellier G. Time to first treatment after colonoscopy in patients suffering from colon or rectum cancer in France. Cancer Epidemiol 2015; 39: 877-884.

3. Yu Z, Pestell TG, Lisanti MP, Pestell RG. Cancer stem cells. Int J Biochem Cell Biol 2012; 44: 2144-2151.

4. Conley SJ, Gheordunescu E, Kakarala P, Newman B, Korkaya H, Heath AN, Clouthier SG, Wicha MS. Antiangiogenic agents increase breast cancer stem cells via the generation of tumor hypoxia. Proc Natl Acad Sci USA 2012; 109: 2784-2789.

5. Jhanwar-Uniyal M, Albert L, McKenna E, Karsy M, Rajdev P, Braun A, Murali R. Deciphering the signaling pathways of cancer stem cells of glioblastoma multiforme: role of Akt/mTOR and MAPK pathways. Adv Enzyme Regul 2011; 51: 164-170.

6. Todaro M, Gaggianesi M, Catalano V, Benfante A, Iovino F, Biffoni M, Apuzzo T, Sperduti I, Volpe S, Cocorullo G,
Gulotta G, Dieli F, De Maria R, Stassi G. CD44v6 is a marker of constitutive and reprogrammed cancer stem cells driving colon cancer metastasis. Cell Stem Cell 2014; 14: 342-356.

7. Lin SP, Lee YT, Yang SH, Miller SA, Chiou SH, Hung MC, Hung SC. Colon cancer stem cells resist antiangiogenesis therapy-induced apoptosis. Cancer Lett 2013; 328: 226-234.

8. Sarvi S, Mackinnon AC, Avlonitis N, Bradley M, Rintoul RC, Rassl DM, Wang W, Forbes SJ, Gregory CD, Sethi T. $\mathrm{CD} 133+$ cancer stem-like cells in small cell lung cancer are highly tumorigenic and chemoresistant but sensitive to a novel neuropeptide antagonist. Cancer Res 2014; 74: 1554-1565.

9. Grosse-Gehling P, Fargeas CA, Dittfeld C, Garbe Y, Alison MR, Corbeil D, Kunz-Schughart LA. CD133 as a biomarker for putative cancer stem cells in solid tumours: limitations, problems and challenges. J Pathol 2013; 229: 355-378.

10. Hashimoto K, Aoyagi K, Isobe T, Kouhuji K, Shirouzu K. Expression of CD133 in the cytoplasm is associated with cancer progression and poor prognosis in gastric cancer. Gastric Cancer 2014; 17: 97-106.

11. Fokas E, Liersch T, Fietkau R, Hohenberger W, Beissbarth T, Hess C, Becker H, Ghadimi M, Mrak K, Merkel S, Raab HR, Sauer R, Wittekind C, Rodel C. Tumor regression grading after preoperative chemoradiotherapy for locally 
advanced rectal carcinoma revisited: updated results of the CAO/ARO/AIO-94 trial. J Clin Oncol 2014; 32: 1554-1562.

12. Sahlberg SH, Spiegelberg D, Glimelius B, Stenerlow B, Nestor M. Evaluation of cancer stem cell markers CD133, CD44, CD24: association with AKT isoforms and radiation resistance in colon cancer cells. PLoS One 2014; 9: 94621.

13. Silva IA, Bai S, McLean K, Yang K, Griffith K, Thomas D, Ginestier C, Johnston C, Kueck A, Reynolds RK, Wicha MS, Buckanovich RJ. Aldehyde dehydrogenase in combination with CD133 defines angiogenic ovarian cancer stem cells that portend poor patient survival. Cancer Res 2011; 71: 3991-4001.

14. Saigusa S, Tanaka K, Toiyama Y, Yokoe T, Okugawa Y, Kawamoto A, Yasuda H, Morimoto Y, Fujikawa H, Inoue Y, Miki C, Kusunoki M. Immunohistochemical features of CD133 expression: association with resistance to chemoradiotherapy in rectal cancer. Oncol Rep 2010; 24: 345-350.

15. Kawamoto A, Tanaka K, Saigusa S, Toiyama Y, Morimoto Y, Fujikawa H, Iwata T, Matsushita K, Yokoe T, Yasuda H, Inoue $\mathrm{Y}$, Miki C, Kusunoki M. Clinical significance of radiation-induced CD133 expression in residual rectal cancer cells after chemoradiotherapy. Exp Ther Med 2012; 3: 403-409.

16. Abdullah LN, Chow EK. Mechanisms of chemoresistance in cancer stem cells. Clin Transl Med 2013; 2: 3 .

17. Hongo K, Kazama S, Sunami E, Tsuno NH, Takahashi K, Nagawa H, Kitayama J. Immunohistochemical detection of CD133 is associated with tumor regression grade after chemoradiotherapy in rectal cancer. Med Oncol 2012; 29: 2849-2857.

18. Kure S, Matsuda Y, Hagio M, Ueda J, Naito Z, Ishiwata T. Expression of cancer stem cell markers in pancreatic intraepithelial neoplasias and pancreatic ductal adenocarcinomas. Int J Oncol 2012; 41: 1314-1324.

19. Angelastro JM, Lame MW. Overexpression of CD133 promotes drug resistance in C6 glioma cells. Mol Cancer Res 2010; 8: 1105-1115.

20. Kojima M, Ishii G, Atsumi N, Fujii S, Saito N, Ochiai A. Immunohistochemical detection of CD133 expression in colorectal cancer: a clinicopathological study. Cancer Sci 2008; 99: 1578-1583.

21. Smith LM, Nesterova A, Ryan MC, Duniho S, Jonas M, Anderson M, Zabinski RF, Sutherland MK, Gerber HP, Van Orden KL, Moore PA, Ruben SM, Carter PJ. CD133/ prominin-1 is a potential therapeutic target for antibodydrug conjugates in hepatocellular and gastric cancers. $\mathrm{Br} \mathrm{J}$ Cancer 2008; 99: 100-109.

\section{${ }^{*}$ Correspondence to}

Jinghua Huang

Department of General Surgery

Affiliated Quanzhou First Hospital

Fujian Medical University

PR China 